\title{
EBF1/PDGFRB Fusion Gene
}

National Cancer Institute

\section{Source}

National Cancer Institute. EBF1/PDGFRB Fusion Gene. NCI Thesaurus. Code C128923.

A fusion gene resulting from a rearrangement of the $q$ arm of chromosome 5 that fuses the first 15 exons of the EBF1 gene to exon 11 of the PDGFRB gene. This fusion may be associated with Ph-like acute lymphoblastic leukemia. 